\title{
Identifying low test-taking effort during low-stakes tests with the new Test-taking Effort Short Scale (TESS) - development and psychometrics
}

\author{
Katrin Schüttpelz-Brauns ${ }^{1 *}$ (D, Martina Kadmon ${ }^{2}$, Claudia Kiessling ${ }^{3}$, Yassin Karay ${ }^{4}$, Margarita Gestmann ${ }^{5}$ \\ and Juliane E. Kämmer ${ }^{6,7}$
}

\begin{abstract}
Background: Low-stakes tests are becoming increasingly important in international assessments of educational progress, and the validity of these results is essential especially as these results are often used for benchmarking. Test scores in these tests not only mirror students' ability but also depend on their test-taking effort. One way to obtain more valid scores from participating samples is to identify test-takers with low test-taking effort and to exclude them from further analyses. Self-assessment is a convenient and quick way of measuring test-taking effort. We present the newly developed Test-taking Effort Short Scale (TESS), which comprises three items measuring attainment value/intrinsic value, utility value, and perceived benefits, respectively.

Methods: In a multicenter validation study with $N=1837$ medical students sitting a low-stakes progress test we analyzed item and test statistics including construct and external validity.

Results: TESS showed very good psychometric properties. We propose an approach using stanine norms to determine a cutoff value for identifying participants with low test-taking effort.

Conclusion: With just three items, TESS is shorter than most established self-assessment scales; it is thus suited for administration after low-stakes progress testing. However, further studies are necessary to establish its suitability for routine usage in assessment outside progress testing.
\end{abstract}

Keywords: Nonconsequential progress testing, Psychometrics, Self-assessment, Short scale, Test-taking effort, Validation study

\section{Background}

\section{Test-taking effort}

Large-scale assessments like the Progress in Reading Literacy Study (PIRLS), the Trends in International Mathematics and Science Study (TIMSS) (see http://timss.bc.edu), the US National Assessment of Educational Progress (NAEP) [1], and the Program for International Student Assessment (PISA) [2, 3] are used as benchmarks of educational systems and student achievement worldwide. This benchmarking process has a substantial impact on the

\footnotetext{
* Correspondence: katrin.schuettpelz-brauns@medma.uni-heidelberg.de ${ }^{1}$ Medical Faculty Mannheim at Heidelberg University, Theodor-Kutzer-Ufer 1-3, 68167 Mannheim, Germany
}

Full list of author information is available at the end of the article reputation of educational systems, as well as on educational reform, policy-making, and resource allocation $[4,5]$. In Germany, for example, the results of PISA 2000 sparked a broad public debate about the German school system and led to the implementation of major reforms [4] despite these large-scale assessments being lowstakes for the participants. Participants did not face any negative consequences if they didn't perform at their best. Yet, students' achievement in any test not only mirrors their underlying ability but also depends on their testtaking effort $[6,7]$, the "extent to which an examinee gives his or her best effort" [8]. Test scores, therefore, do not only reflect ability but also test-taking effort, with corresponding effects on test validity $[9,10]$. 
In high-stakes testing, the consequences for test-takers can be significant, potentially leading to high test-taking effort and, in turn, better performance. In low-stakes testing, in contrast, the test result has no consequences for testtakers [9], which may decrease the subjective task value, resulting in lower motivation or test-taking effort and, in turn, lower performance $[10,11]$. Nevertheless, low-stakes testing is becoming increasingly important, not only

- (1) in large-scale international assessments (e.g., NAEP, TIMSS, PISA) [10, 12], but also

- (2) in the evaluation of curricula [9],

- (3) in piloting new test items for high-stakes testing, and

- (4) in empirical research [9].

Progress testing in medical education is an example of low-stakes testing. In Germany and Austria, for example, progress tests are used as a means of formative assessment [13] and are therefore low stakes. Progress tests are administered repeatedly during undergraduate training (e.g., once per semester), with students of all semesters undergoing the same test. In Germany and Austria, for example, 15 medical faculties administer the Berlin Progress Test (BPT) [13, 14] with about 10,000 students twice a year. Faculties use the information gathered to evaluate, develop, and compare their curricula and to provide students with feedback on their current level of knowledge and development [13-17]. As the conclusions drawn from these tests may be far reaching, it is important for faculties and researchers to keep track of test-taking effort and to potentially exclude participants with low test-taking effort from their analyses.

\section{How to reliably measure test-taking effort}

Currently, there are three approaches to measuring testtaking effort. The first is to measure response time to test items, under the assumption that participants with low test-taking effort will take less time to think about their answers and will therefore answer questions faster than participants with high test-taking effort [9]. Measuring response time is convenient in computer-based assessment. However, it does not differentiate between low test-taking effort and test-takers with high expertise, who are able to identify keywords in the question and decide within seconds whether they can answer it or not. A second approach is appropriateness measurement, whereby the probability of answer patterns is calculated on the basis of either estimated empirical models or theoretical parametric/nonparametric item response models [18-20]. Lack of fit between a test-taker's answer pattern and the model is then attributed to lack of motivation and low test-taking effort [9]. There are, however, two weaknesses to this approach: (1) A misfit between test- taker data and model does not necessarily imply a lack of motivation and test-taking effort but may also imply differential item functioning, i.e. test-takers with different learning strategies or experiences may show distinct response patterns despite exerting the same high testtaking effort. In this case, some test-takers would be erroneously identified as showing low effort. (2) Calculating misfit of a test-takers' answer pattern in large samples requires sophisticated statistical skills. Whereas this expertise is in place in large-scale assessments, it is not always present in experimental/social research.

In the third and currently most widely used approach, test-taking effort is measured with self-assessment scales. In contrast to the response time approach, selfassessment allows fast experts to be differentiated from test-takers with low test-taking effort. Furthermore, it does not require sophisticated statistical skills. The drawback of this third approach is that, like any other self-report method, it is vulnerable to motivational processes. Long self-reports, for example, may decrease the motivation for meaningful answers or to answer at all. Thus, not responding can in itself be an expression of low test-taking effort [21]. Self-assessment scales therefore need to be very short to mitigate motivational effects on answers. An overview of published selfassessment scales is given in Table 1. However, the established instruments are rather long, with an average of 15 items. As large-scale assessments often take several hours, any test effort self-reports administered immediately afterwards should be short, in order to prevent low compliance or low motivation resulting in invalid results [9]. The shortest instrument, the Effort Thermometer (Table 1), has just three items but is not suited for filtering out test-takers with low test-taking effort as its purpose is to measure intraindividual differences of effort in assessments with different stakes; additionally, it has no theoretical framework and no reported psychometrics.

\section{Construction of the test-taking effort short scale (TESS)}

We used a theory-driven approach to test construction to develop TESS [22].

Expectancy-value theory as conceptual framework to explain test-taking effort.

Expectancy-value theory-a well-established and empirically validated psychological theory-has already been used to construct self-report instruments measuring test-taking effort, such as the Student Opinion Scale (see Table 1). According to expectancy-value theory, achievement-related choices (e.g., effort, performance, or persistence) depend on the test-taker's expectation of success and the subjective task value [23]. Subjective task value consists of four components:

(1) Attainment value is the importance of doing well. 
Table 1 Self-report measures of test-taking effort

\begin{tabular}{|c|c|c|c|c|}
\hline Instrument & No. items & Subscales & What is measured & Psychometrics \\
\hline Effort Thermometer [12] & 3 10-point Likert items & No subscales & $\begin{array}{l}\text { Individual test effort, anchored } \\
\text { against a personal situation in } \\
\text { which maximum effort was } \\
\text { applied }\end{array}$ & Not reported \\
\hline $\begin{array}{l}\text { Online Motivation } \\
\text { Questionnaire (OMQ) [47] }\end{array}$ & 32 4-point Likert items & $\begin{array}{l}\text { Mood scale } \\
\text { Self-efficacy } \\
\text { Success expectancy } \\
\text { Perceived utility } \\
\text { Task attraction } \\
\text { Intended efforts } \\
\text { Task anxiety scale }\end{array}$ & $\begin{array}{l}\text { Test-taking effort in the context } \\
\text { of performance assessment } \\
\text { (part 1: pre-test, part 2: post-test) }\end{array}$ & $\begin{array}{l}\text { Confirmatory factor analysis } \\
\text { revealed that seven factors } \\
\text { could be distinguished } \\
\text { empirically; proven validity } \\
\text { and acceptable reliability }\end{array}$ \\
\hline $\begin{array}{l}\text { Questionnaire of Current } \\
\text { Motivation (QCM) [48] }\end{array}$ & 18 7-point Likert items & $\begin{array}{l}\text { Situational interest } \\
\text { Anxiety } \\
\text { Challenge } \\
\text { Probability of success }\end{array}$ & $\begin{array}{l}\text { Current motivation during a } \\
\text { learning situation }\end{array}$ & $\begin{array}{l}\text { Sufficient to excellent } \\
\text { reliability } 2 \\
\text { Proven validity }\end{array}$ \\
\hline Student Opinion Scale (SOS) & 10 5-point Likert items & $\begin{array}{l}\text { Importance } \\
\text { Effort }\end{array}$ & $\begin{array}{l}\text { Motivation, administered as a } \\
\text { post-test after students have } \\
\text { completed achievement tests [49] }\end{array}$ & $\begin{array}{l}\text { Proven validity and good } \\
\text { to excellent reliability [50] }\end{array}$ \\
\hline
\end{tabular}

(2) Intrinsic value is the enjoyment of engaging with the task.

(3) Utility value depends on how well a task fits into an individual's future plans. In low-stakes assessment, it may depend on how relevant a test is to a test-taker-in terms of being useful for assessing one's learning progress, for instance.

(4) The variable cost assesses to what extent engaging in one task limits access to other activities, as well as emotional costs.

Studies with students from elementary and secondary schools, colleges, and universities have provided empirical evidence for expectancy-value theory. For example, Trautwein et al. showed that the expectancy and value components predicted achievement in secondary school students [24] and Chiu and Wang found that they predicted continued use of web-based learning even when desisting had no consequences [25]. Perceived utility value has been shown to predict performance (e.g., course points in an English class, [26]; or correctly solved multiplication problems [27]). Likewise, the variables usefulness and importance have significantly predicted test-taking effort and performance in several tests with undergraduate students [28].

\section{Constructing content-valid items}

In low-stakes assessment, wanting to achieve the best possible results is an expression of attainment value as well as intrinsic value. Item 1 of TESS (see Table 2) measures this factor. Utility value is captured by item 2, which asks how useful the test is to the student (see Table 2). If low-stakes tests fit into an educational program, their perceived costs will be lower, as they will be seen as equally important as other parts of the program.
Item 3 taps this factor by asking students whether the test is a valuable part of their education (see Table 2).

All three items were constructed as 5-point Likert items with the anchors 1 "fully disagree" to 5 "fully agree." Thus, TESS consists of three items, the first measuring attainment value and intrinsic value, the second measuring utility value, and the third measuring perceived benefits (i.e., reverse-coded costs).

\section{Aims}

Our first aim was to develop a short test-effort selfassessment scale that is capable of measuring test effort in low-stakes testing with high reliability and validity. Our second aim was to conduct a validation study for the scale developed.

\section{Methods}

To validate the newly developed TESS, we conducted a study with $N=1837$ medical students involved in regular progress testing at eight medical schools in Germany and Austria. We analyzed item and test statistics of TESS, i.e. mean, standard deviation, difficulty, and discrimination as well as reliability, homogeneity, construct validity, and external validity. We standardized values to identify participants with low test-taking effort. Additionally, we analyzed response rates to determine whether non-response to TESS is diagnostic of low testtaking effort (see also [21].

\section{Sample}

All students who participated in the Berlin Progress Test (BPT) $[13,14]$ at eight medical schools in Germany and Austria in winter semester 2015/2016 $(N=4624)$ were invited to participate in this study. Of these, 1837 students (40\%) completed the questionnaire and were 
Table 2 Item statistics

\begin{tabular}{|c|c|c|c|c|c|}
\hline Item & M & SD & $p_{i}$ & $r_{\text {cis }}$ & $H_{i s}$ \\
\hline $\begin{array}{l}\text { 1. I want to achieve the best possible results in the test. [German: Ich möchte beim PTM } \\
\text { die bestmöglichen Ergebnisse erreichen.] }\end{array}$ & 3.14 & 1.36 & 0.47 & 0.70 & 0.68 \\
\hline 2. I think the progress test is useful. [German: Ich finde den PTM sinnvoll.] & 3.27 & 1.35 & 0.50 & 0.76 & 0.72 \\
\hline $\begin{array}{l}\text { 3. The test is a valuable part of my education. [German: Der PTM ist ein wertvoller Teil } \\
\text { meines Studiums.] }\end{array}$ & 2.48 & 1.25 & 0.31 & 0.75 & 0.73 \\
\hline
\end{tabular}

$M$ mean, $S D$ standard deviation, $p_{i}$ difficulty, $r_{c i s}$ discriminatory power (part-whole corrected), $H_{i s}$ Mokken homogeneity coefficient of item with scale

included in the validation study. Of the 1654 participants who reported their sex, 639 were male (39\%) and 1015 were female (61\%); 183 participants did not report their sex. Mean age was 23.81 years $(S D=3.99$, range: $17-56)$. The demographic distribution of our sample resembled that of the population of medical students in Germany (mean age $M=23.7$, sex distribution: 61\% female [29]. We therefore consider our sample to be representative of the medical student population.

\section{Procedure}

Students were invited to voluntarily complete TESS as part of a more extensive study not pertinent to this manuscript administered after the BPT. The 9-page questionnaire was administered in the same format as the progress test, namely in either computer-based or paper-based format. In total, 857 computer-based (47\%) and 980 paper-based (53\%) questionnaires were completed. The Ethical Review Board of Medical Faculty Mannheim, Heidelberg University, approved the study (2015-542 N-MA).

\section{Material}

TESS was used to measure students' test-taking effort in the BPT via self-assessment. TESS is included in the supplementary material (see Additional file 1). Further measures were included in the post-test study to assess the construct validity and external validity of TESS.

\section{Construct validity}

Following Campbell and Fiske [30], we assessed the construct validity of TESS by determining its convergent and discriminant validity. Convergent validity assesses the degree to which different tests designed to measure the same construct are, in fact, related. Discriminant validity assesses the degree to which tests designed to measure different constructs are, in fact, unrelated.

To determine convergent validity, we used the following established and new measures to assess test-takers' intrinsic motivation (relates to item 1), the perceived usefulness of the BPT (relates to item 2) and its perceived benefits (relates to item 3 ). High correlations with the respective TESS item would indicate convergent validity on the item level.
Intrinsic motivation was measured using the Short Scale of Intrinsic Motivation, which consists of twelve 5point Likert items and has been shown to be reliable and valid [31]. A sample item is "I found the BPT very interesting" [German: "Ich fand den PTM sehr interessant"].

Perceived usefulness was measured with a German translation of the Perceived Usefulness Scale, which consists of seven 5-point Likert items and has shown excellent psychometric properties in two studies [32]. A sample item is "I expect the BPT to be useful for learning" [German: "Ich erwarte, dass mir der PTM beim Lernen nützlich sein wird"].

Perceived benefits were assessed with a selfconstructed 5-point Likert item targeting costs: "To what extent do you feel that sitting the BPT keeps you from your other duties?" [German: "In welchem Maße werden Sie durch den PTM in Ihren anderen Verpflichtungen eingeschränkt?"].

To determine discriminant validity, we additionally assessed a variable that is conceptually independent of test-taking effort but still related to test performance, namely, learning strategy use. Learning strategies are action plans used to control and monitor one's learning. They are used to reach learning goals efficiently and are oriented towards learning and not towards taking a test. As test-taking effort depends on the situation [33], it should not strongly relate to the learning strategy use.

Learning strategy use was measured with the Repetition scale of the Learning Strategies in Undergraduate Training test (German: Lernstrategien im Studium, LIST), which consists of eight 6-point Likert items and has been shown to be reliable and valid [34]. A sample item is "I learn the content of texts by reading them again and again" [German: "Ich präge mir den Lernstoff von Texten durch Wiederholen ein”].

\section{External validity}

To obtain external criteria of participants' test-taking effort, we asked them to report the test score and test time of their previous BPT. Both measures would be expected to be low if test-taking effort was low $[9,14]$. The BPT test score is calculated as the number of correct answers minus the number of incorrect answers. Test time is the time taken on the test. 
All data used in this study can be found in the supplementary material (see Additional file 2).

\section{Response rates}

As completion of TESS was voluntary, participants could in principle answer between 0 and 3 TESS items. Response rates indeed varied between 0 and 3 TESS items. For further analyses, responders were defined as those with 3 completed TESS items; non-responders as those with 0 completed items (despite participating in the study). We excluded all participants who answered 1 or 2 items from our analysis of response rates.

In order to analyze whether non-response to TESS was diagnostic of low test-taking effort, we compared the BPT test times and test scores of non-responders with those of responders with low TESS scores (objectively indicating low test-taking effort) and with those of responders with high TESS scores. If findings showed that non-responders do not differ from participants with low TESS scores in terms of the BPT variables, but that they do differ from participants with high TESS scores, this will indicate that nonresponse to TESS is diagnostic of low test-taking effort.

\section{Statistical analysis}

For each of the three TESS items, we determined the mean, standard deviation, difficulty, discriminatory power, and item-scale homogeneity. Difficulty $p_{i}$ per item was calculated as the sum of squared scores divided by the number of participants multiplied by the squared maximum score (in the case of a 5-point Likert item $=25$ ) [35].

Corrected item-scale correlation $\left(r_{\text {cis }}\right)$ was used to compute item discrimination. This correlation is categorized as moderate if $.30 \leq r_{\text {cis }}<.50$ and as high if $\mathrm{r}_{\text {cis }} \geq .50$ [36]. Cronbach's alpha $(\alpha)$ was used to estimate the reliability of TESS. Reliability is categorized as low if $\alpha<.80$, moderate if $.80 \leq \alpha<.90$, and high if $\alpha \geq .90$ [36]. Scale homogeneity $\left(H_{\mathrm{s}}\right)$ as well as item-scale homogeneity $\left(\mathrm{H}_{\mathrm{is}}\right)$ was analyzed using Mokken scale analysis, which analyzes the goodness of fit to the Guttman structure. A scale is unscalable if $H_{\mathrm{s}}<.30$, weak if $.30 \leq H_{\mathrm{s}}<.40$, medium if $.40 \leq H_{\mathrm{s}}<.50$, and strong if $H \geq .50$. The same applies to $H_{\text {is }}$ [37].

To determine convergent validity, we calculated Spearman rank correlations between the three TESS items and the Short Scale of Intrinsic Motivation, the Perceived Usefulness Scale, and the self-constructed item tapping the costs of the BPT, respectively. To estimate discriminant validity, we calculated product-moment correlations between the TESS score and the score on the Repetition scale of the LIST. Effect size $r^{2}$ was calculated and effects were categorized as large for $r^{2} \geq 0.25$, as moderate for $0.09 \leq r^{2}<0.25$, and as small for $0.01 \leq r^{2}<0.09$ [38].
External validity was estimated by group comparisons of low/high BPT test scores and short/long BPT test time. To this end, participants were ranked with respect to each of those variables. Students in the top and bottom $20 \%$ of the sample were then compared with respect to their indicated test effort with one-way analysis of variance.

In low-stakes assessment, a binominal distribution of test-taking effort scores can be expected, with a first peak at very low scores for participants who did not take the test seriously and a second peak at average scores. Therefore, we used stanine norms-which are directly derived from percentile rank-to determine a cutoff value for participants with low test-taking effort. Stanine values of 1 and 2 mean arbitrary values.

Additionally, we used one-way ANOVAs with post hoc tests (Scheffé tests) to compare the non-responders with the groups of responders with low vs. high test-taking effort according to stanine standardization. Effects were categorized as large for $\eta^{2} \geq 0.1379$, as medium for $0.0588 \leq \eta^{2}<0.1379$ and, and as small for $0.0099 \leq \eta^{2}<0.0588$ [38].

IBM Statistics SPSS 23 was used to calculate the results. The R package Mokken [39] was used to compute the Mokken homogeneity coefficient.

\section{Results}

\section{Item statistics}

Item means ranged from 2.48 to 3.27 with an average of 2.96 and a standard deviation of 1.32 (see Table 2). Item difficulty ranged between medium (item 3) and high (item 2). The discriminatory power and item-scale homogeneity of each item was high.

\section{Test statistics}

\section{Reliability and homogeneity}

The reliability of TESS was moderate with Cronbach's $\alpha$ of 0.86 . The Mokken homogeneity of the TESS scale was high $(H=0.71)$.

\section{Construct validity}

The correlations of the three TESS items with the corresponding external criteria of convergent validity were moderate (for item 3) to large (for items 1 and 2). The TESS score correlated significantly but with no practical effect with the Repetition scale of the LIST, providing evidence for discriminant validity (see Table 3 ).

\section{External validity}

Ranked in terms of BPT test time, the lower $20 \%$ of participants $(N=314$; fast performers) needed $41 \mathrm{~min}$ $(\mathrm{SD}=21 \mathrm{~min})$ on average to complete the progress test; the upper $20 \%$ of participants $(N=262$; slow performers $)$ needed $2 \mathrm{~h}$ and $40 \mathrm{~min}(\mathrm{SD}=17 \mathrm{~min})$ of the maximum of $3 \mathrm{~h}$ an examinee can expend on the BPT. These two groups differed significantly in terms of their TESS 
Table 3 Correlations of single TESS items and the TESS score with external criteria

\begin{tabular}{lllrr}
\hline Internal criterion & External criterion & $N$ & $r$ & $p$ \\
\hline Convergent validity & & & $r^{2}$ \\
TESS item 1 & Short Scale of Intrinsic Motivation [31] & 1333 & .52 & $<.001$ \\
TESS item 2 & Perceived Usefulness Scale [32] (German translation) & 1377 & .57 & $<.001$ \\
TESS item 3 & Cost $^{*}$ & 1380 & -.34 & $<.001$ \\
Discriminant validity & & & .32 \\
TESS score & Repetition scale of the LIST [34] & 1195 & .06 & $<.05$ \\
\hline
\end{tabular}

$N$ number of participants, $r$ product-moment correlation, $p$-value, $r^{2}$ effect size, ${ }^{\#}$ item "To what extent do you feel that sitting the BPT keeps you from your other duties?" (reverse coded)

scores, with fast performers having lower TESS scores than slow performers (see Table 4).

Ranked in terms of BPT test scores, the lower $20 \%$ of participants $(N=126$; poor performers) achieved an average score of $1.46(\mathrm{SD}=2.87)$; the upper $20 \%(N=130$; high performers) an average score of $92.46(\mathrm{SD}=30.11)$. Poor performers had significantly lower TESS scores than high performers (see Table 4).

\section{Standardization}

TESS scores with a stanine norm of 1 or 2, indicating percentile ranks of 0 to $11 \%$, can be interpreted as signaling low test-taking effort. TESS scores with a stanine norm of 8 or 9 , indicating percentile ranks of 90 to $100 \%$, can be interpreted as indicating high test-taking effort [40]. As shown in Table 5, a TESS score of 1 corresponded to a stanine score of 1 or 2, indicating low test-taking effort, whereas TESS scores higher than 4 corresponded to a stanine score of 8 or 9 , indicating high test-taking effort. A TESS score of 1 refers to an individual who chose 1 on the 5-point Likert-scale for all three of the TESS items.

\section{Response rates}

Of the 1837 study participants, 1373 answered all three TESS questions (75\%; i.e., responders), whereas 437 did not answer any (24\%; i.e., non-responders). Twentyseven participants answered one or two TESS questions. With respect to the administration format, 804 (82\%) of the 980 participants who did the test on paper answered all three TESS questions and 163 (17\%) did not answer any, whereas only 569 (66\%) of the 857 participants who did the test on a computer answered all three questions and 274 (32\%) did not answer any (see Fig. 1). Twentyseven participants answered one or two TESS questions, 13 of them on paper and 14 on computer.

Mean BPT test time in non-responders was significantly higher than in participants with low test-taking effort and significantly lower than in participants with high test-taking effort (see Table 6). In terms of mean $\mathrm{BPT}$ test scores, in contrast, there was no significant difference between the non-responders and the participants with either low or high test-taking effort (see Table 6).

\section{Discussion}

Performance in low-stakes tests occasionally depends on examinees' test-taking effort. One approach to obtaining valid scores is to identify examinees with low test-taking effort and to exclude their answers from analyses. In this article, we introduced the Test-taking Effort Short Scale (TESS), a short self-assessment scale designed to measure test-taking effort in low-stakes progress testing, in particular. We assessed the scale's psychometric properties in a multicenter validation study (eight medical schools) with $N=1837$ medical students taking a regular progress test.

TESS was developed on the basis of expectancyvalue theory [23] and adapted to the special situation

Table 4 TESS scores in extreme groups

\begin{tabular}{|c|c|c|c|c|}
\hline \multirow[b]{2}{*}{ External criterion } & \multirow[b]{2}{*}{ Group } & \multicolumn{3}{|c|}{ TESS values } \\
\hline & & $M(S D)$ & $N$ & ANOVA \\
\hline \multirow[t]{2}{*}{ BPT test time } & Fast performers $^{a}$ & $2.29(1.06)$ & 257 & $F(1)=258.70 ; p<0.001 ; \eta^{2}=0.35$ \\
\hline & Slow performers ${ }^{b}$ & $3.70(0.87)$ & 237 & \\
\hline \multirow[t]{2}{*}{ BPT test score } & Poor performers ${ }^{c}$ & $2.66(1.25)$ & 100 & $F(1)=27.03 ; p<0.001 ; \eta^{2}=0.12$ \\
\hline & High performers ${ }^{d}$ & $3.50(1.08)$ & 110 & \\
\hline
\end{tabular}

$N$ number of participants (the difference to the $N$ s reported in the text is due to the fact that not all participants belonging to the extreme groups also reported their test time and test score), $M$ mean TESS scores; SD: standard deviation, BPT Berlin Progress Test

${ }^{\mathrm{a}} \mathrm{M}=0: 41, \mathrm{SD}=0: 21$ to take the test

${ }^{\mathrm{b}} \mathrm{M}=2: 40, S D=0: 17$ to take the test

test score of $\mathrm{M}=1.46, \mathrm{SD}=2.87$

$d_{\text {test score of } M=92.46, S D=30.11}$ 
Table 5 Percentile ranks of TESS scores and corresponding stanine values

\begin{tabular}{lllll}
\hline TESS score & $N$ & Percentile rank & Stanine & Interpretation \\
\hline 1 & 157 & 11.4 & 1,2 & Low TTE \\
1.33 & 55 & 15.4 & 3 & \\
1.67 & 67 & 20.3 & 3 & \\
2 & 95 & 27.2 & 4 & \\
2.33 & 88 & 33.6 & 4 & \\
2.67 & 119 & 42.3 & 5 & \\
3 & 141 & 52.6 & 5 & \\
3.33 & 157 & 64 & 6 & \\
3.67 & 136 & 73.9 & 6 & \\
4 & 144 & 84.4 & 7 & High TTE \\
4.33 & 81 & 90.3 & 8 & High TTE \\
4.67 & 60 & 94.7 & 8 & \\
5 & 73 & 100 & 9 & \\
\hline
\end{tabular}

TTE test-taking effort

of low-stakes assessment. With just three 5-point Likert items, it is much shorter than most other instruments measuring test-taking effort. This brevity is of considerable advantage in lengthy low-stakes assessments, helping to combat decreasing motivation and thus to increase response rates.

Our findings showed that TESS has very good psychometric properties. Reliability was moderate and scale homogeneity proved to be high. Convergent validity was moderate to high. The reason for item 3 showing only moderate convergent validity may be that, lacking a standardized scale to measure the cost of test-taking, we used a one-item measure to determine the convergent validity of the TESS costs item. This one-item measure directly assesses the cost of taking a low-stakes test, but its validity and reliability are unknown. The TESS items were not significantly related to any of the discriminant variables. Due to large sample sizes TESS score correlated significantly with the external correlation. However correlations were so small that there is no indication for a practical effect. Our findings thus confirmed the construct validity of TESS. Furthermore, our stanine standardization approach to identifying participants with low test-taking effort provided evidence for the external validity of TESS. Our sample was representative of the population of medical students in Germany with respect to age and sex; standardizing was thus justified.

Seventy-five percent of the participants in this study answered all three TESS items. Our response rate analysis showed that non-responders could not be allocated to either the high or the low test-taking effort group in terms of their test times and test scores. Thus, our sample included a rather high number of students whose test-taking effort could not be determined. A reason for this may be that TESS was embedded in an extensive questionnaire administered after a test lasting up to $3 \mathrm{~h}$ (BPT). Had TESS been administered alone, the response rate might have been higher. Indeed, $91 \%$ of examinees typically answer the voluntary evaluation form regularly administered after the BPT, which comprises 4 multiple choice items. Thus, further investigations are needed before our results can be generalized to routine usage in assessment within and beyond medical progress testing.

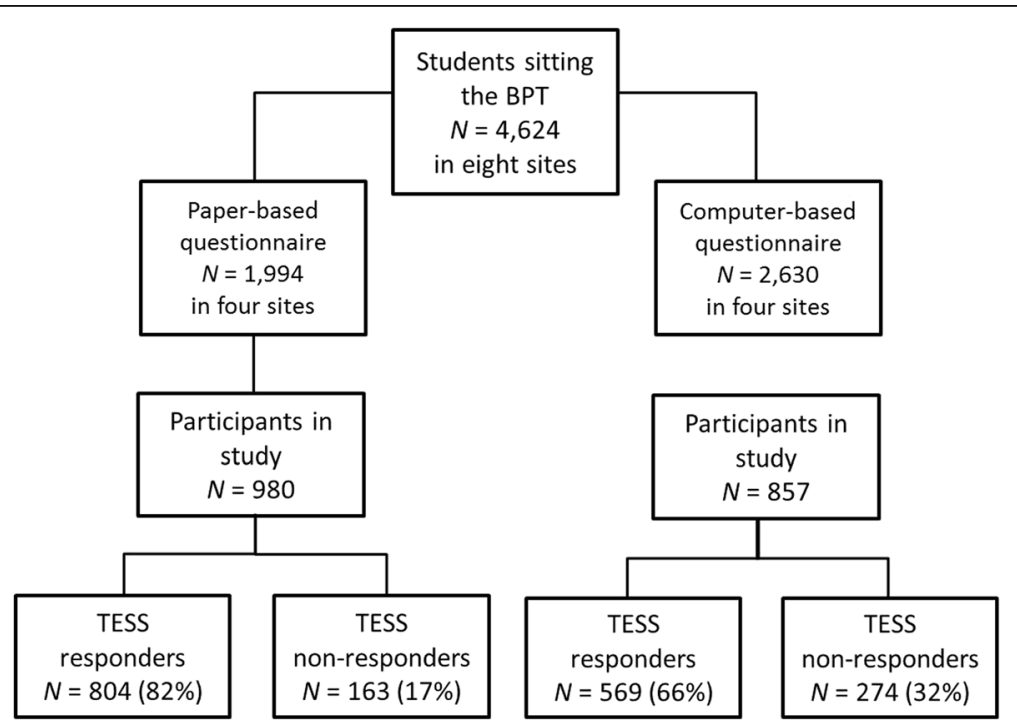

Fig. 1 Flowchart showing participant numbers separately for computer- and paper-based administration; TESS responders are defined as participants who answered all three TESS items; non-responders are defined as participants who did not answer any TESS items (despite participating in the study) 
Table 6 Comparison of different groups of (non)-responding in TESS

\begin{tabular}{llllll}
\hline External criterion & Group & $N$ & $M(S D)$ & ANOVA & Scheffé test \\
\hline (A) BPT test time (hours:minutes) & Non-responders (G1) & 122 & $1: 22(0: 53)$ & $F(2)=85.40 ; p<0.01, \eta^{2}=0.29$ & $G 2<G 1<G 3$ \\
& Low TTE (G2) & 100 & $0: 58(0: 40)$ & & \\
& High TTE (G3) & 198 & $2: 01(0: 34)$ & & \\
& Non-responders (G1) & 71 & $35.77(45.14)$ & $F(2)=9.31, p<0.01, \eta^{2}=0.08$ & $G 1=G 2$ and G1=G3 \\
& Low TTE (G2) BPT test score & 52 & $22.04(36.08)$ & \\
& High TTE (G3) & 106 & $49.27(33.44)$ & & \\
\hline
\end{tabular}

Comparison of non-responders in TESS (G1) with responders with low test-taking effort (G2) and responders with high test-taking effort (G3), as defined by (A) BPT test scores or (B) BPT test time

$N$ number of participants, $M$ mean, SD Standard deviation, $T T E$ test-taking effort, low vs. high TTE determined by stanine standardization, see Table 5

With respect to administration format, we found that there were fewer non-responders in the paper-based format than in the computer-based format. Several studies comparing computer-based vs. paper-based evaluation of teaching have yielded similar results [41, 42]. One reason for this difference could be survey fatigue in the context of online surveys [43]. As computer-based assessment becomes increasingly widespread, further studies are needed to identify factors influencing response rates in computer-based assessment.

Certain limitations of our study warrant consideration. First, like every self-assessment instrument, TESS may be subject to social desirability bias. A 9-page questionnaire added to the assessment may have impacted TESS-related data beyond survey fatigue. Nevertheless, TESS proved to have excellent psychometric properties, is able to differentiate between low test-taking effort and high expertise, and does not require a high level of statistical skill. Second, data on the external criteria (BPT test time and BPT test scores) were collected as selfreports on past test participation. If less motivated students respond carelessly, such self-report measures may lack accuracy [8]. Objective measurement of the actual test-taking time and score may have provided more valid external criteria. Our approach may also be less sensitive in terms of identifying low test-taking effort via TESS. Due to privacy protection in this study, however, objective measures of BPT test time and BPT test score were not available. A second study is planned to circumvent these drawbacks.

The three-item TESS is suitable for administration after low-stakes progress tests. A TESS score of 1 identifies participants with low test-taking effort, whose results therefore threaten the validity of the assessment. Using TESS rather than response time or appropriateness measurement to statistically identify test-takers with low test-taking effort shows test-takers that administrators are concerned about the problem of low test-taking effort. In our experience, test-takers with average testtaking effort are likely to increase their effort if they know that the results of a low-stakes assessment will not be negatively influenced by test-takers with low testtaking effort.

Further studies are needed to investigate the following aspects:

- applicability of TESS in low-stakes assessment other than progress testing and after translation into other languages;

- standardization of scores in other low-stakes assessments, contexts, and populations;

- response rates when TESS is the only instrument administered after a low-stakes assessment;

- reasons for lower response rates in computer-based than paper-based assessment;

- sensitivity and specificity of low test-taking effort as measured by TESS with an objective measurement of low test-taking effort.

\section{Conclusion}

The results of large-scale assessments can have a considerable impact on education policy and practice [5]. As largescale assessment is usually low stakes, individual test-takers' performance may be influenced not only by their ability but by their test-taking effort [44]. Using a reliable and parsimonious tool such as TESS to filter out participants with low test-taking effort could be a good way of improving the validity of the conclusions drawn from large-scale assessments. Furthermore, as health professions education moves towards more formative assessment strategies (van der Vleuten, programmatic assessment $[45,46]$ ) measures that facilitate assessing the rigor of test questions used in formative assessments will be needed in many settings.

\section{Additional files}

Additional file 1: Questionnaire of TESS. (DOCX $18 \mathrm{~kb}$ )

Additional file 2: Raw data with all variables used in this study. (XLSX $150 \mathrm{~kb})$ 


\section{Abbreviations}

BPT: Berlin progress test; TESS: Test-taking effort short scale; TTE: Test-taking effort

\section{Acknowledgements}

We thank Johann Arias, Matthias Holzer, Daniela Kleisch, and Hans-Georg Kraft for implementing the questionnaire at their medical faculties, Herta Flor for critically reading the manuscript, and Susannah Goss for editing it.

\section{Funding}

This research did not receive any specific grant from funding agencies in the public, commercial, or not-for-profit sectors.

\section{Availability of data and materials}

All relevant data and unpublished material are included in the additional files.

\section{Authors' contributions}

KSB designed the study and wrote the first draft of the manuscript together with JEK. JEK and CK supervised the study design. MK, MG, YK and CK were responsible for data collection. KSB is responsible for data analyses. All authors carefully read the manuscript, made critical and substantial revisions, and gave their approval for publication.

\section{Ethics approval and consent to participate}

The Ethical Review Board of Medical Faculty Mannheim, Heidelberg University, approved the study (2015-542 N-MA). All participants were orally informed about the study and received written information about the study, anonymity and voluntary participation on the questionnaire. Students could decline to fill out the questionnaire if they did not consent. Students who did not fill out the questionnaire were not identified or recognized. Therefore, we assume that participation was voluntarily.

\section{Competing interests}

Dr. Kadmon serves on the journal's Editorial Board as Associate Editor. All other authors declare that they have no competing interests.

\section{Publisher's Note}

Springer Nature remains neutral with regard to jurisdictional claims in published maps and institutional affiliations.

\section{Author details}

${ }^{1}$ Medical Faculty Mannheim at Heidelberg University, Theodor-Kutzer-Ufer 1-3, 68167 Mannheim, Germany. ${ }^{2}$ Carl von Ossietzky University Oldenburg, Carl-von-Ossietzky-Straße 9-11, 26129 Oldenburg, Germany. ${ }^{3}$ Brandenburg Medical School Theodor Fontane, Fehrbelliner Straße 38, 16816 Neuruppin, Germany. ${ }^{4}$ Medical Faculty, University of Cologne, Joseph-Stelzmann-Straße 20 (Building 42), 50931 Cologne, Germany. ${ }^{5}$ Medical Faculty, University of Duisburg-Essen, Hufelandstraße 55, 45147 Essen, Germany. ${ }^{6}$ AG Progress Test Medizin, Charité Universitätsmedizin Berlin, Hannoversche Straße 19, 10115 Berlin, Germany. ${ }^{7}$ Center for Adaptive Rationality, Max Planck Institute for Human Development, Lentzeallee 94, 14195 Berlin, Germany.

\section{Received: 5 July 2017 Accepted: 20 April 2018}

Published online: 08 May 2018

\section{References}

1. Campbell JR, VoelkI KE, Donahue PL. NAEP 1996 trends in academic progress. Achievement of U.S. students in science, 1969 to 1996; mathematics, 1973 to 1996; reading, 1971 to 1996; writing, 1984 to 1996. In: Report no. NCES-97-985. Educational Testing Service /National Center for education statistics; 1998. https://nces.ed.gov/nationsreportcard/pdf/ main1996/97985r.pdf. Accessed 28 June 2017.

2. OECD. Measuring student knowledge and skills. A new framework for assessment: OECD Publishing; 1999. https://www.oecd.org/edu/school/ programmeforinternationalstudentassessmentpisa/33693997.pdf. Accessed 28 June 2017

3. OECD. The PISA 2003 assessment framework. Mathematics, reading, science and problem solving knowledge and skills: OECD Publishing; 2003. https://uww. oecd.org/edu/school/programmeforinternationalstudentassessmentpisa/ 33694881.pdf. Accessed 28 June 2017.
4. Breakspear S. The policy impact of PISA. An exploration of the normative effects of international benchmarking in school system performance. OECD education working papers no. 71. Organization for Economic co-operation and Development. 2012. http://dx.doi.org/10.1787/5k9fdfaffr28-en. Accessed 28 June 2017

5. Fullan M. Large-scale reform comes of age. J Educ Change. 2009; https://doi.org/10.1007/s10833-009-9108-z.

6. Sundre DL, Kitsantas AL. An exploration of the psychology of the examinee: can examinee self-regulation and test-taking motivation predict consequential and non-consequential test performance? Contemp Educ Psychol. 2004; https://doi.org/10.1016/S0361-476X(02)00063-2.

7. Waskiewicz RA. Pharmacy students' test-taking motivation-effort on a low-stakes standardized test. Am J Pharm Educ. 2011; https://doi.org/10. 5688/ajpe75341.

8. Wise SL, DeMars CE. Low examinee effort in low-stakes assessment: problems and potential solutions. Educ Assess. 2005; https://doi.org/10. 1207/s15326977ea1001_1.

9. Wise SL, Kong X. Response time effort: a new measure of examinee motivation in computer-based tests. Appl Meas Educ. 2005; https://doi.org/ 10.1207/s15324818ame1802_2.

10. Barry CL, Horst SJ, Finney SJ, Brown AR, Kopp JP. Do examinees have similar test-taking effort? A high-stakes question for low-stakes testing. Int J Test. 2005; https://doi.org/10.1080/15305058.2010.508569.

11. Hawthorne KA, Bol L, Pribesh S, Suh Y. Effects of motivational prompts on motivation, effort, and performance on a low-stakes standardized test. Res Pract Assess. 2015;10:30-8.

12. Baumert J, Demmrich A. Test motivation in the assessment of student skills: the effects of incentives on motivation and performance. Eur J Psychol Educ. 2001; https://doi.org/10.1007/BF03173192.

13. Nouns ZM, Georg W. Progress testing in German speaking countries. Med Teach. 2010; https://doi.org/10.3109/0142159X.2010.485656.

14. Osterberg K, Kölbel S, Brauns K. Der progress test Medizin: Erfahrungen an der Charité berlin [the progress test Medizin: years of experience at the Charité berlin]. GMS Z Med Ausbild. 2006; http://www.egms.de/static/pdf/ journals/zma/2006-23/zma000265.pdf. Accessed 28 June 2017

15. Freeman A, van der Vleuten C, Nouns Z, Ricketts C. Progress testing internationally. Med Teach. 2010; https://doi.org/10.3109/0142159X.2010. 485231.

16. Ricketts C, Freeman A, Pagliuca G, Coombes L, Archer J. Difficult decisions for progress testing: how much and how often? Med Teach. 2010; https://doi.org/10.3109/0142159X.2010.485651.

17. Schauber SK, Hecht M, Nouns ZM, Kuhlmey A, Dettmer S. The role of environmental and individual characteristics in the development of student achievement: a comparison between a traditional and a problem-basedlearning curriculum. Adv Health Sci Educ. 2015; https://doi.org/10.1007/ s10459-015-9584-2.

18. Meijer RR, Muijtjens AMM, van der Vleuten CPM. Nonparametric person-fit research: some theoretical issues and an empirical example. Appl Meas Educ. 1996; https://doi.org/10.1207/s15324818ame0901_7.

19. Meijer RR, Sijtsma K. Methodology review: evaluating person fit. Appl Psychol Meas. 1996; https://doi.org/10.1177/01466210122031957.

20. Meijer RR. Diagnosing item score patterns on a test using item response theory-based person-fit statistics. Psychol Methods. 1996; https://doi.org/ 10.1037/1082-989X.8.1.72.

21. Karay Y, Schauber S, Stosch C, Schuettpelz-Brauns K. Can computer-based assessment enhance the acceptance of formative multiple choice exams? A utility analysis. Med Teach. 2012; https://doi.org/10.3109/0142159X.2012. 652707.

22. Burisch M. Approaches to personality inventory construction: a comparison of merits. Am Psychol. 1984; https://doi.org/10.1037/0003-066X.39.3.214.

23. Wigfield A, Eccles JS. Expectancy-value theory of achievement motivation. Contemp Educ Psychol. 2000; https://doi.org/10.1006/ceps.1999.1015.

24. Trautwein U, Marsh HW, Nagengast B, Lüdtke O, Nagy G, Jonkmann K. Probing for the multiplicative term in modern expectancy-value theory: a latent interaction modeling study. J Educ Psychol. 2012; https://doi.org/ 10.1037/a0027470.

25. Chiu CM, Wang ETG. Understanding web-based learning continuance intention: the role of subjective task value. Inf Manag. 2008; https://doi.org/ 10.1016/j.im.2008.02.003.

26. Greene BA, Miller RB, Crowson HM, Duke BL, Akey KL. Predicting high school students' cognitive engagement and achievement: contributions of 
classroom perceptions and motivation. Contemp Educ Psychol. 2004; https://doi.org/10.1016/j.cedpsych.2004.01.006.

27. Hulleman CS, Godes O, Hendricks BL, Harackiewicz JM. Enhancing interest and performance with a utility value intervention. J Educ Psychol. 2010; https://doi.org/10.1037/a0019506

28. Cole JS, Bergin DA, Whittaker TA. Predicting student achievement for low stakes tests with effort and task value. Contemp Educ Psychol. 2008; https://doi.org/10.1016/j.cedpsych.2007.10.002.

29. Kolbert-Ramm C, Ramm M, Zur Studiensituation im Fach Humanmedizin. Ergebnisse des 11. Studierendensurveys [On the situation of students of human medicine: Results of the $11^{\text {th }}$ student survey]. Sonderauswertung für den Medizinischen Fakultätentag (MFT) der Bundesrepublik Deutschland: Universität Konstanz: Arbeitsgruppe Hochschulforschung, Büro für Sozialforschung; 2011. http://www.mft-online.de/files/medizinberichtgesamt. pdf. Accessed 28 June 2017.

30. Campbell DT, Fiske DW. Convergent and discriminant validation by the multitrait-multimethod matrix. Psychol Bull. 1959; https://doi.org/10.1037/ h0046016.

31. Wilde M, Batz K, Kovaleva A, Urhahne D. Überprüfung einer Kurzskala intrinsischer motivation (KIM) [testing a short scale of intrinsic motivation]. Z Did NatWiss. 2009;15:31-45.

32. Davis FD. Perceived usefulness, perceived ease of use, and user acceptance information technology. MIS Q. 1989; https://doi.org/10.2307/249008.

33. Wise $S L$, Ma L, Kingsbury G, Hauser $C$. An investigation of the relationship between time of testing and test-taking effort. Natl Counc Meas Educ. 2010; https://www.nwea.org/content/uploads/2010/04/An-Investigation-of-theRelationship-between-Time-of-Testing-and-Test-Taking-Effort.pdf. Accessed 28 June 2017.

34. Boerner S, Seeber G, Keller H, Beinborn P. Lernstrategien und Lernerfolg im Studium: Zur Validierung des LIST bei berufstätigen Studierenden (learning strategies and successs: validation of the LIST with part-time students). Z EntwPsychol Pädag Psychol. 2005; https://doi.org/10.1026/0049-8637.37.1.17.

35. Bortz J, Döring N. Forschungsmethoden und evaluation für human- und Sozialwissenschaftler [research methods and evaluation for human and social scientists]. 4. Aufl. Heidelberg: Springer; 2006.

36. Weise G. Psychologische Leistungstests. Ein Handbuch für Studium und Praxis. Band 1: Intelligenz - Konzentration - Spezielle Fähigkeiten [Psychological achievement tests]. 1. Aufl. Göttingen: Hogrefe; 1975.

37. Mokken RJ. A theory and procedure of scale analysis: with applications in political research. The Haque: Walter De Gruyter; 1971.

38. Cohen J. Statistical power analysis for the behavioral sciences. $2^{\text {nd }}$ ed. Hillsdale: Lawrence Erlbaum Associates; 1988.

39. Van der Ark LA. Mokken scale analysis in R. J Stat Software. 2007; https://doi.org/10.18637/jss.v020.111.

40. Kaplan RM, Saccuzzo DP. Psychological testing: principles, applications, and issues. $8^{\text {th }}$ ed. Belmont: Wadsworth Publishing; 2013.

41. Layne BH, Decristoforo JR, Mcginty D. Electronic vs. traditional student rating of instruction. Res High Educ. 1999; https://doi.org/10.1023/A: 1018738731032

42. Mertler CA. Patterns of response and nonresponse from teachers to traditional and web surveys. Pract Asses Res Eval. 2003;8(22):1-17.

43. Adams MJD, Umbach PD. Nonresponse and online student evaluations of teaching: understanding the influence of salience, fatigue, and academic environments. Res High Educ. 2012; https://doi.org/10.1007/s11162-0119240-5.

44. Eklöf H. Skill and will: test-taking motivation and assessment quality. Assess Educ. 2010; https://doi.org/10.1080/0969594X.2010.516569.

45. Schuwirth LWT, van der Vleuten CPM. Programmatic assessment: from assessment of learning to assessment for learning. Med Teach. 2011; https://doi.org/10.3109/0142159X.2011.565828.

46. Van der Vleuten CPM, Schuwirth LWT, Driessen EW, Dijkstra J, Tigelaar D, Baartman LKJ, van Tartwijk J. A model for programmatic assessment fit for purpose. Med Teach. 2012; https://doi.org/10.3109/0142159X.2012.652239.

47. Crombach MJ, Boekaerts M, Voeten MJM. Online measurement of appraisals of students faced with curricular tasks. Educ Psychol Meas. 2003; https://doi.org/10.1177/0013164402239319.
48. Rheinberg F, Vollmeyer R, Burns BD. FAM: Ein Fragebogen zur Erfassung aktueller motivation in Lern- und Leistungssituationen [a questionnaire to assess current motivation in learning situations]. Diagn. 2001; https://doi.org/10.1026//0012-1924.47.2.57.

49. Sundre DL, Moore DL. The student opinion scale: a measure of examinee motivation. Assess Update. 2002;14(1):8-9.

50. Thelk AD, Sundre DL, Horst SJ, Finney SJ. Motivation matters: using the student opinion scale to make valid inferences about student performance. J Gen Educ. 2009; https://doi.org/10.1353/jge.0.0047.

\section{Ready to submit your research? Choose BMC and benefit from:}

- fast, convenient online submission

- thorough peer review by experienced researchers in your field

- rapid publication on acceptance

- support for research data, including large and complex data types

- gold Open Access which fosters wider collaboration and increased citations

- maximum visibility for your research: over $100 \mathrm{M}$ website views per year

At BMC, research is always in progress.

Learn more biomedcentral.com/submissions 